\title{
Management of pregnancy in women with rheumatoid arthritis
}

\begin{abstract}
"For
unplanned

pregnancies,

cease

teratogenic

medications

immediately

and refer to a

genetics

counsellor and

maternal-fetal

medicine

specialist"

$\mathrm{R}$ heumatoid arthritis (RA) is a common condition which occurs more frequently in women than men. ${ }^{1}$ Its prevalence is about $2 \%$ in Australia, and this is predicted to increase to $3 \%$ by $2032 .{ }^{2}$ Therefore, the need to manage pregnancy in a woman with RA is not an uncommon clinical scenario. Clinicians must be aware of the teratogenicity of certain disease-modifying antirheumatic drugs (DMARDs) used to treat RA, and must ensure that women taking these drugs are using reliable contraception. Clinicians also have an important role to play in prepregnancy counselling to facilitate informed decision making. We, ${ }^{3}$ and others, ${ }^{4}$ have identified unmet information needs among women with RA, including needs relating to contraception, pregnancy planning, pregnancy and early parenting. The aim of our review is to highlight pertinent issues in managing pregnancy in women with RA.
\end{abstract}

Gene-Siew Ngian

MB BS, FRACP, PhD

Andrew M Briggs

$\mathrm{BSc}(\mathrm{PT}) \mathrm{Hons}, \mathrm{PhD}$

Ilana N Ackerman

PhD, BPhysio(Hons)

Sharon Van Doornum

MBBS, MD, FRACP

1 Department of Medicine

(Royal Melbourne Hospital),

University of Melbourne

Melbourne, VIC.

2 Arthritis and Osteoporosis

Victoria, Research and

Knowledge

Melbourne, VIC

3 Melbourne EpiCentre,

Melbourne Health and

University of Melbourne,

Melbourne, VIC.

gene-siew.ngian@ mh.org.au

doi: 10.5694/mjal5.00365

\section{Effect of RA on fertility and pregnancy}

Despite having normal ovarian reserves, ${ }^{5}$ women with RA have fewer children than women in a control group, ${ }^{6}$ and take longer to conceive. ${ }^{7}$ The reasons for smaller family size have not been fully elucidated but may include personal choice, uncontrolled inflammatory disease, sexual dysfunction secondary to RA and the effects of non-steroidal anti-inflammatory drugs on ovulation and implantation. ${ }^{8}$ Clinicians should be aware of the possibility of subfertility, discuss this issue with prospective parents, and refer to reproductive specialists, when appropriate.

A recent registry-based study reported increased rates of spontaneous abortion in women with RA, although previous studies suggested no increased risk. ${ }^{9}$ Increased rates of prematurity, pre-eclampsia, caesarean delivery and infants with a low birth weight have been reported in women with RA. ${ }^{10-13}$ A Dutch study found that women taking prednisolone had higher rates of preterm delivery, and those with high disease activity were more likely to have caesarean delivery and infants with a low birth weight, but patients with well controlled RA had pregnancy outcomes comparable with those of the general population. ${ }^{14}$

\section{Effect of pregnancy and lactation on RA}

It was reported as early as 1938 that RA disease activity improved in $90 \%$ of women during pregnancy, ${ }^{15}$ and numerous subsequent studies have reported similar observations. A more recent prospective study of pregnant women with RA supports this finding, but suggests that rates of remission are more modest than traditionally thought, and that complete remission is uncommon. ${ }^{16}$ In this study, $39 \%$ of patients had flared by 26 weeks

\section{Summary}

- Rheumatoid arthritis (RA) disease activity may improve during pregnancy but postpartum flares are common.

- Patients taking disease-modifying antirheumatic drugs should be counselled about effective contraception.

- Knowledge about drug safety in pregnancy is limited but the Therapeutic Goods Administration categories and online resources are a guide to the data currently available.

- Begin prepregnancy counselling as early as possible to allow for cessation of teratogenic medications and optimisation of RA disease control.

- For unplanned pregnancies, cease teratogenic medications immediately and refer to a genetic counsellor and maternal-fetal medicine specialist for risk assessment and advice.

postpartum, confirming another long-held observation that women with RA are at increased risk of flare in the postpartum period. Women should be educated about the likelihood of postpartum flares and safe strategies to manage these events.

Because prolactin, a pituitary hormone integral to breastfeeding, is proinflammatory in animal models, ${ }^{17}$ the effect of breastfeeding on postpartum RA activity has been investigated. Despite two small studies suggesting that breastfeeding was associated with postpartum flares of RA, ${ }^{18,19}$ subsequent larger studies have not confirmed this association. ${ }^{20,21}$

\section{Prepregnancy counselling}

Given the teratogenicity of several DMARDs, treating practitioners have an obligation to ensure that patients with RA are counselled regularly about the importance of reliable contraception while taking these agents. ${ }^{22}$ One study found that $28 \%$ of women taking methotrexate (MTX) or leflunomide (LEF) used ineffective contraception. ${ }^{23}$ Another reported that despite $84 \%$ of women receiving correct contraceptive advice, one-third of women taking MTX or LEF were not using any contraception. $^{24}$

It is estimated that up to $49 \%$ of pregnancies in the general population are unintended. ${ }^{25}$ If an unplanned pregnancy occurs in the setting of exposure to teratogenic drugs, the medications should be ceased immediately and the patient referred to a genetic counsellor and maternal-fetal medicine specialist for discussion of risk and further management. 
Women with RA may question their practitioner about the possibility of RA inheritance. Controlled cohort studies have shown a relative risk of RA of 1.5-4.5 in firstdegree relatives. ${ }^{26}$ Despite this modest increase in relative risk, patients can be reassured that the absolute risk of RA in their offspring remains small.

Good disease control before conception results in the best chance of low disease activity during pregnancy and a reduced risk of postpartum flare. ${ }^{16}$ Teratogenic medications need to be ceased and the several months it may take to ensure stability on a new drug regimen should be taken into account when planning pregnancy. Recommendations about cessation of medications before conception also extend to men on MTX and LEF (although there are no reports of teratogenicity in the children of men on either drug), ${ }^{27,28}$ and sulfasalazine (SSZ), which is known to reversibly impede spermatogenesis and reduce sperm motility and quality. ${ }^{29}$ A preconception referral to a maternal-fetal medicine specialist or obstetrician with an interest in high-risk pregnancy should also be considered.

\section{Safety of drug therapy in pregnancy}

Because of ethical concerns, pregnant and lactating women are specifically excluded from premarketing drug trials. Most pregnancy drug safety data are, therefore, derived from animal studies or postmarketing surveillance, case reports and large registries. In Australia, the Therapeutic Goods Administration pregnancy classification is used to categorise the safety of drugs in pregnancy (https://www.tga.gov.au/australian-categorisationsystem-prescribing-medicines-pregnancy). It is not a hierarchical system, ie, it is not implied that a category B drug is safer than a category $C$ drug. Although the pregnancy classification is widely used, in certain situations it is of limited use to clinicians in determining suitability of therapy. For example, while hydroxychloroquine (HCQ) and MTX are both category D drugs, only HCQ is considered safe in pregnancy, according to Australian practice guidelines. $^{30}$

Of the DMARDs in current use, MTX and LEF are contraindicated in pregnancy and breastfeeding, and HCQ and SSZ are compatible with pregnancy. ${ }^{31}$ Of the biological agents, tumour necrosis factor (TNF) inhibitors may be continued until pregnancy is confirmed, with use in later gestation determined on a case-by-case basis, ${ }^{32}$ but all other biological agents should be avoided. If TNF inhibitors are used during pregnancy, live vaccinations should be avoided in the infant until 6 months of age, because of the risk of immunosuppression. ${ }^{33}$

Given the evolving nature of drug safety data, online resources are particularly helpful for clinicians. MotherToBaby (www.mothertobaby.org), a service of the Organization of Teratology Information Specialists, and LactMed (http:// toxnet.nlm.nih.gov/ newtoxnet/lactmed. htm), run by the United States National Library of Medicine, are two useful and regularly updated websites.

Competing interests: This was an investigator-initiated review, but we received research grants from UCB and AbbVie. Neither company had any input into the design or execution of our review.

Provenance: Not commissioned; externally peer reviewed.

(c) 2016 AMPCo Pty Ltd. Produced with Elsevier B.V. All rights reserved.

References are available online at www.mja.com.au. 
1 Firestein GS, Kelley WN. Kelley's textbook of rheumatology. 8th ed. Philadelphia, PA: Saunders/Elsevier; 2009.

2 Arthritis and Osteoporosis Victoria. A problem worth solving. Elsternwick: Arthritis and Osteoporosis Victoria, 2013.

3 Ackerman IN, Jordan JE, Van Doornum S, et al. Understanding the information needs of women with rheumatoid arthritis concerning pregnancy, post-natal care and early parenting: A mixed-methods study. BMC Musculoskelet Disord 2015; 16: 194.

4 Neame R, Hammond A, Deighton C. Need for information and for involvement in decision making among patients with rheumatoid arthritis: a questionnaire survey. Arthritis Rheum 2005; 53: 249-255.

5 Brouwer J, Laven JS, Hazes JM, et al. Levels of serum antiMüllerian hormone, a marker for ovarian reserve, in women with rheumatoid arthritis. Arthritis Care Res (Hoboken) 2013; 65: 1534-1538.

6 Skomsvoll JF, Ostensen M, Baste V, et al. Number of births, interpregnancy interval, and subsequent pregnancy rate after a diagnosis of inflammatory rheumatic disease in Norwegian women. J Rheumatol 2001; 28: 2310-2314.

7 Jawaheer D, Zhu JL, Nohr EA, et al. Time to pregnancy among women with rheumatoid arthritis. Arthritis Rheum 2011; 63: 1517-1521.

8 Provost M, Eaton JL, Clowse ME. Fertility and infertility in rheumatoid arthritis. Curr Opin Rheumatol 2014; 26: 308-314.

9 Wallenius M, Salvesen K, Daltveit A, et al. Miscarriage and stillbirth in women with rheumatoid arthritis. $J$ Rheumatol 2015; 42: 1570-1572.

10 Skomsvoll JF, Ostensen M, Irgens LM, et al. Obstetrical and neonatal outcome in pregnant patients with rheumatic disease. Scand J Rheumatol 1998; 107 (Suppl): 109-112.

11 Chakravarty EF, Nelson L, Krishnan E. Obstetric hospitalizations in the United States for women with systemic lupus erythematosus and rheumatoid arthritis. Arthritis Rheum 2006; 54: 899-907.

12 Lin HC, Chen SF, Chen YH. Increased risk of adverse pregnancy outcomes in women with rheumatoid arthritis: a nationwide population-based study. Ann Rheum Dis 2010; 69: 715-717.

13 Wallenius M, Skomsvoll JF, Irgens LM, et al. Pregnancy and delivery in women with chronic inflammatory arthritides with a specific focus on first birth. Arthritis Rheum 2011; 63: 1534-1542.

14 de Man YA, Hazes JMW, van der Heide $\mathrm{H}$, et al. Association of higher rheumatoid arthritis disease activity during pregnancy with lower birth weight: results of a national prospective study. Arthritis Rheum 2009; 60: 3196-3206.

15 Hench PS. The ameliorating effect of pregnancy of chronic atrophic (infectious rheumatoid) arthritis, fibrositis and intermittent hydrarthrosis. Mayo Clin Proc 1938; 13: 161-180.

16 de Man YA, Dolhain RJEM, van de Geijn FE, et al. Disease activity of rheumatoid arthritis during pregnancy: results from a nationwide prospective study. Arthritis Rheum 2008; 59: 1241-1248.

17 Lavalle C. Prolactin - a hormone with immunoregulatory properties that leads to new therapeutic approaches in rheumatic diseases. J Rheumatol 1992; 19: 839-841.

18 Brennan $P$, Silman A. Breast-feeding and the onset of rheumatoid arthritis. Arthritis Rheum 1994; 37: 808-813.
19 Barrett $\mathrm{JH}$, Brennan P, Fiddler M, et al. Breast-feeding and postpartum relapse in women with rheumatoid and inflammatory arthritis. Arthritis Rheum 2000; 43: 1010-1015.

20 Pikwer M, Bergstrom U, Nilsson JA, et al. Breast feeding, but not use of oral contraceptives, is associated with a reduced risk of rheumatoid arthritis. Ann Rheum Dis 2009; 68: 526-530.

21 Adab P, Jiang CQ, Rankin E, et al. Breastfeeding practice, oral contraceptive use and risk of rheumatoid arthritis among Chinese women: the Guangzhou Biobank Cohort Study. Rheumatology 2014; 53: 860-866.

22 Chakravarty EF, Sanchez-Yamamoto D, Bush TM. The use of disease modifying antirheumatic drugs in women with rheumatoid arthritis of childbearing age: a survey of practice patterns and pregnancy outcomes. J Rheumatol 2003; 30: 241-246.

23 Clowse MEB, Chakravarty EF, Costenbader KH, et al. Contraception use in women with rheumatoid arthritis [abstract]. Arthritis Rheum 2011; 63 (Suppl 10): 2109.

24 Ostensen M, von Esebeck M, Villiger PM. Therapy with immunosuppressive drugs and biological agents and use of contraception in patients with rheumatic disease. J Rheumatol 2007; 34: 1266-1269.

25 Henshaw SK. Unintended pregnancy in the United States. Fam Plann Perspect 1998; 30: 24-29.

26 Frisell T, Holmqvist M, Kallberg $\mathrm{H}$, et al. Familial risks and heritability of rheumatoid arthritis: role of rheumatoid factor/ anti-citrullinated protein antibody status, number and type of affected relatives, sex, and age. Arthritis Rheum 2013; 65: 2773-2782.

27 Weber-Schoendorfer C, Hoeltzenbein M, Wacker E, et al. No evidence for an increased risk of adverse pregnancy outcome after paternal low-dose methotrexate: an observational cohort study. Rheumatology 2014; 53: 757-763.

28 Brent RL. Teratogen update: reproductive risks of leflunomide (Arava); a pyrimidine synthesis inhibitor: counseling women taking leflunomide before or during pregnancy and men taking leflunomide who are contemplating fathering a child. Teratology 2001; 63: 106-112.

29 O'Morain C, Smethurst P, Dore CJ, et al. Reversible male infertility due to sulphasalazine: studies in man and rat. Gut 1984; 25: 1078-1084.

30 Therapeutics Committee, Australian Rheumatology Association. Prescriber's information on medications for rheumatic diseases in pregnancy. Sydney: Australian Rheumatology Association, 2011.

31 Bermas BL. Non-steroidal anti inflammatory drugs, glucocorticoids and disease modifying anti-rheumatic drugs for the management of rheumatoid arthritis before and during pregnancy. Curr Opin Rheumatol 2014; 26: 334-340.

32 Williams M, Chakravarty EF. Rheumatoid arthritis and pregnancy: impediments to optimal management of both biologic use before, during and after pregnancy. Curr Opin Rheumatol 2014; 26: 341-346.

33 Hassid B, Mahadevan U. The use of biologic therapy in pregnancy: a gastroenterologist's perspective. Curr Opin Rheumatol 2014; 26: 347-353. 